\title{
Mechanical and Surface Morphology Properties of Low Density Polyethylene Composites Filled with Organic Materials
}

\author{
Onyenweaku Chinonso Emmanuel, Nwokoye Joy Nwando, Chris-Okafor Pauline Uchechukwu* \\ Department of Pure and Industrial Chemistry, Nnamdi Azikiwe University, Awka, Nigeria \\ Email address: \\ pu.chrisokafor@unizik.edu.ng (Chris-Okafor P. U.) \\ ${ }^{*}$ Corresponding author \\ To cite this article: \\ Onyenweaku Chinonso Emmanuel, Nwokoye Joy Nwando, Chris-Okafor Pauline Uchechukwu. Mechanical and Surface Morphology \\ Properties of Low Density Polyethylene Composites Filled with Organic Materials. American Journal of Mechanical and Materials \\ Engineering. Vol. 5, No. 1, 2021, pp. 1-4. doi: 10.11648/j.ajmme.20210501.11
}

Received: December 8, 2020; Accepted: January 14, 2020; Published: March 10, 2021

\begin{abstract}
The effects of coconut husk and mango seed shell filler blend which are considered as agricultural wastes on the mechanical properties of Low Density Polyethylene (LDPE) composites were studied. These fillers which are of plant origin, organic, cheap to acquire, available, and biodegradeable were incorporated into LDPE polymer resin for the fabrication of biodegradeable LDPE polymer composites. Varying percentages of the fillers, $0 \%, 5 \%, 10 \%, 15 \%$ and $20 \%$ were added to the LDPE polymer resins to produce biodegradeable LDPE polymer composites through injection moulding machine. The mechanical properties such as tensile strength, flexural strength, compression strength and hardness test were tested for. The surface morphology of the composites was also tested for via scanning electron microscope. The results showed that the fillers had positive impacts on the mechanical properties of the polymer composites by improvement in the flexural strength and hardness. The use of such cheap, available and biodegradeable raw materials can decrease the high cost of production of LDPE products, and aid the production of more eco friendly polymer composites.
\end{abstract}

Keywords: Low Density Polyethylene (LDPE), Coconut Husk Shell, Mango Seed Shell, Mechanical Properties and Surface Morphology

\section{Introduction}

The extensive exploit of polymeric materials such as plastics in various application like packaging, building materials, medicine, sports, automobile, domestic etc. is increasing rapidly nowadays as a result of effective modification of properties of plastics using additives. There enable polymer materials to overcome its pacific deficiencies during service and lower the high rate dependency of petroleum - based plastic due to depletion ofour natural resources, and new environmental regulation, which demand the search for materials that are compactable with the environment [1]. Among all the additives being used in the modification of plastic properties, extruding and reinforcing fillers (either in fibrous or particular form) have played significant role. Recently, the sources of fillers for polymeric materials have been shifted to agricultural materials [2] or natural product (as an alternative to expensive and toxic inorganic filters) due to their availability, low cost, ecofriendly and biodegradability.

Polymer composites are the physical combination of two or more materials of some or different categories of materials (out of them one must be polymer) to form a multi-plastic system with improved properties from the individual components without losing their own identity [3]. A composite material is a microscopic or macroscopic combination of two or more defined materials with a recognizable interface between them. A particulate composite consists of a matrix reinforced with a dispersed phase in form of particles, like groundnut shell, mango seed shells, coconut husk etc. which can be dispensed in a harder matrix to improve machinability and reduce coefficient of friction [4, 5]. One advantage of a composite is that two or more materials could be combined to take advantage of the good 
characteristics of each of them. Composites are gaining a wide range of application in engineering because of the following advantages: weight savings, corrosion resistance, easy manufacturing, low temperature processing, possibility of producing novel shapes reduced parts and long fatigue [6]. The attempt to produce better plastics led to incorporation of filler (inorganic and organic) into plastics with a view to obtain a plastic composite whose constituents act synergistically to withstand the challenges, thereby making plastics more reliable during use or processing. Generally, the composite properties are influenced by many factors such as filler characteristics, filler content, and interfacial adhesion and dispersion due to combination of more than one material [7]. The production of plastic composites is experiencing a chain growth in the plastic industries due to their renewable resources, biodegradability, low energy consumption, low cost of industrial economic importance, possibility of high filling level, high specific properties and the growing global environmental concern [8,9].

Thus, this study is aimed at harnessing the potentials of mango seed shell and coconut husk as fillers for the production of low density polyethylene composites.

\section{Materials and Methods}

\section{Materials}

The low density polyethylene resins for this study were obtained from CEE-Plast Industries Limited, Aba, Abia State, Nigeria. The LDPE matrix was in crystalline form. Low density polyethylene is easy to process; itsstability and flow ability makes it an ideal polymer for injection molding technique. The coconut husk and mango seed shells were both sourced locally from Agulu market in Awka, Aniocha Local Government Area, Anambra State, Nigeria. The mango seed shells and coconut husk were washed with soap and rinsed thoroughly with clean water, broken down into smaller sizes and sun dried for a week. The fillers were crushed and ground separately for several times and sieved locally using a muslin cloth so as to obtain fine powdered mixture. This process was repeated until desired quantity was obtained. The particle size of the fillers was determined by an electronic sieve of mesh size of $80 \mu \mathrm{m}$.

Preparation of LDPE composites

The low density polyethylene composites were prepared by thoroughly weighing of $200 \mathrm{~g}, 190 \mathrm{~g}, 180 \mathrm{~g}, 170 \mathrm{~g}, 160 \mathrm{~g}$ of crystalline low density polyethylene resins and mixing with filler blend of coconut husk and mango seed shell in the ratio $50: 50$ at a varying gram weight of $10 \mathrm{~g}, 20 \mathrm{~g}, 30 \mathrm{~g}, 40 \mathrm{~g}(0 \%, 5 \%$, $10 \%, 15 \%, 20 \%$ ) respectively. The low density polyethylene pellets were melted and homogenized with the filler in an injection moulding machine with a rectangular shaped mould. The low density polyethylene works with temperature of $180^{\circ} \mathrm{C}$. The homogenized mixture was fed into the barrel via the hopper. The LDPE filled composites were produced as rectangular shaped sheets and cut into the desired dumb bell shapes for mechanical properties characterization.

Determination of Physico-Mechanical properties of LDPE composites

\section{Flexural Test}

The flexural strength of a material is defined as its ability to resist deformation under load. Flexural properties were carried out as described in American standard testing and measurement, method D-790, using the Instron universal testing machine.

\section{Hardness test}

Hardness is measured by the distance of indentation and recovery that occurs when an indentor is pressed into the surface under constant load and is then released. The surface hardness of the polymer composites were determined according to the American standard testingand measurement methodASTM D2240 by the meansof Avery hardness testing machine, type 6406, NUMBER E65226, manufactured by Avery Birmingham, England. The corresponding value of the diameter of the indentation at the surface was recorded and the hardness was calculated with the formula as Birnell Hardness Number measured in $\mathrm{N} / \mathrm{mm}^{2}$.

Tensile Test

Tensile strength is the capacity of a material to withstand loads tending to elongate, in other words tensile strength is therefore measured by the maximum stress that a material can withstand while being stretched or pulled before breaking. Tensile properties test were carried out as described in American Standard testing and measurement, method D638, using the Instron universal testing machine.

Compression Test

Compression strength is the capacity of a material to withstand loads tending to reduce size, in other words compression strength resist compression (being pushed together). Compressive test was carried out as prescribed in American standard testing and measurement, method D-2240

Scanning Electron Microscopy (SEM)

Scanning electron microscopy (SEM) is one of the main techniques for nanomaterials characterization, due to its ability to provide morphological details of materials at nanometer resolution.

\section{Results and Discussion}

\section{Mechanical Properties of LDPE Composites Flexural Strength}

Flexural strength of low density polyethylene as shown in Figure 1 indicates an increase in flexural properties.

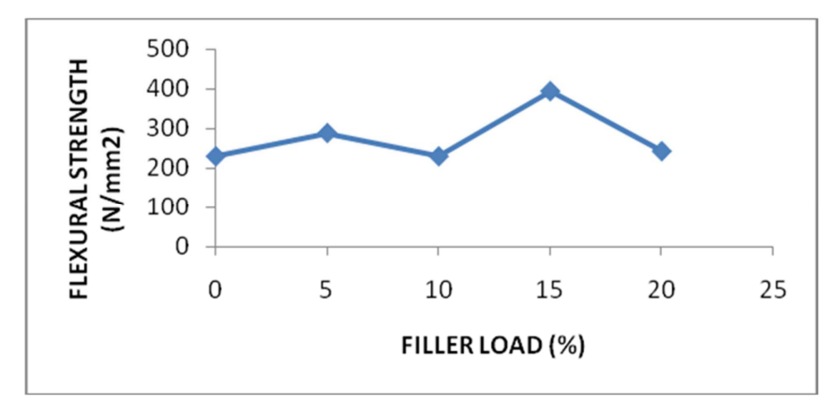

Figure 1. Effect of coconut husk and mango seed shell on the flexural strength of the reinforced polyethylene (LDPE) composites. 
It can be deduced that the reinforced composite of $15 \%$ filler content has the highest flexural strength when compared to the unfilled $0 \%$ filler composite having the lowest flexural strength, this increase might be due to even dispersion of filler in the polymer matrix and the cellulosic nature of the filler $[10,11]$. This is in agreement with this present study and shows that coconut husk and mango seed shell powdered filler blend can be used as filler in improving the flexural properties of LDPE composites.

Hardness test result

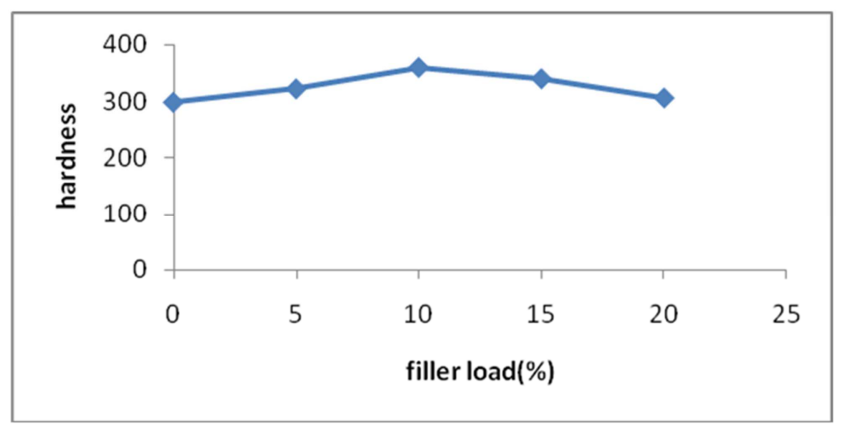

Figure 2. Effect of coconut husk and mango seed shell on the hardness of the reinforced low density polyethylene LDPE composites.

The hardness result in Figure 2, showed an increase in the value hardness, with $10 \%$ filler load giving the highest value for hardness. Thus, this increased value of hardness indicates that the presence of these fillers in the polymer matrix improves surface stiffness of the composites and it reduces the elasticity of the polymer chain resulting to a more rigid polymer. This work agrees with some other works $[12,13]$ which observed an increase in hardness value as filler content increase.

Tensile Strength

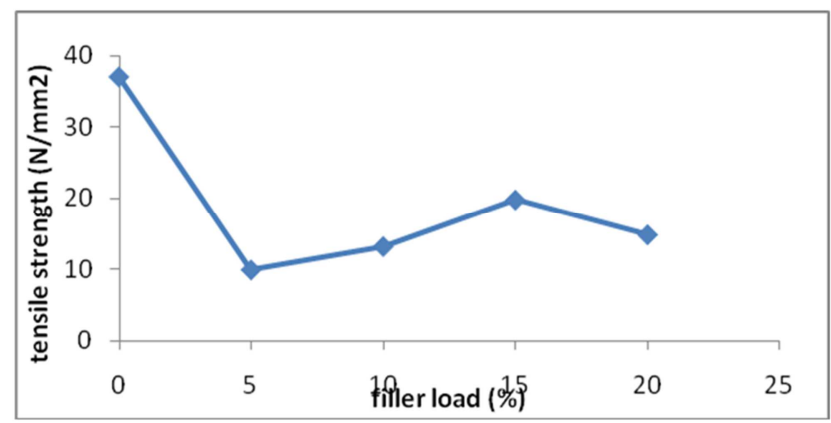

Figure 3. Effect of coconut husk and mango seed shell on the tensile strength of the reinforced low density polyethylene (LDPE) composites.

From the tensile test result, it was observed that the fillers caused a decrease in the tensile strength of the polymer composites, with a varying increase in tensile strength from 5\% filler content to $15 \%$ filler content of the polymer matrix as shown in Figure 3. This may be due to poor interaction between the filler polymer matrix. It could also be attributed to the uneven dispersion created by the fillers in the matrix. It is seen to be in accordance with the results of some other authors [14-16]. This is in agreement with the present study and shows that the filler blend results in a decrease in tensile properties of LDPE composites.

Compression strength

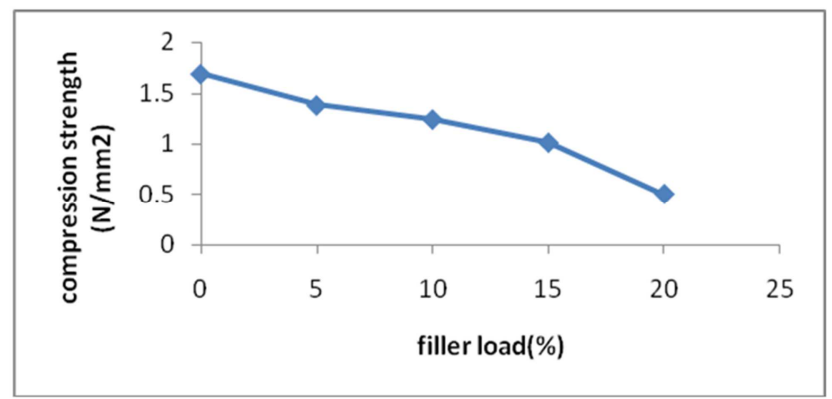

Figure 4. Effect of the mixed fillers on the compression strength of the reinforced low density polyethylene (LDPE) composite.

Figure 4 indicated a decrease in compression strength with an increase in percentage filler content. The result for compression of $0 \%$ polymer composite is higher than that of $5,10,15,20 \%$ filler reinforced composites. This decrease in compressive strength of the low density polyethylene composite could be due to the filler particle that filled the interstitial voids thereby creating no space for external force applied in the form of test force, thus reducing the compressive strength. This reduction could be as a result of weak adhesion between the polymer and the filler, lack of coupling agent and particle size, since the incorporation of this filler blend reduces the compressive strength. This work also agrees with this author [17] who worked on effects of fillers of animal origin on the physico-mechanical properties of utility polymer which recorded a decrease in compression strength with increase of percentage filler contents.

The Micrographs of Scanning Electron Microscope of Coconut Husk and Mango Seed Shell Reinforced Low Density Polyethylene.

The surface morphology of coconut husk and mango seed shells reinforced Low Density Polyethylene was taken through scanning electron microscope.

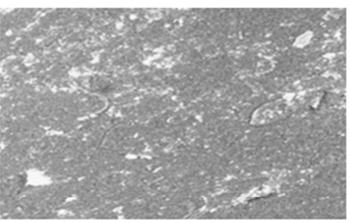

a: $0 \%$ LDPE composites.

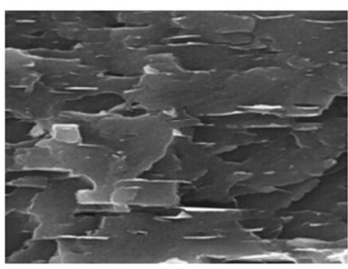

c: $10 \%$ LDPE composites.

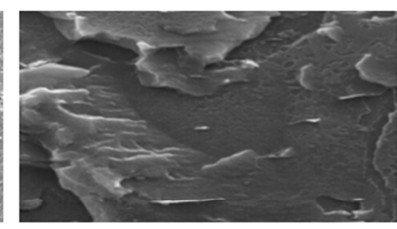

b: 5\% LDPE composites.

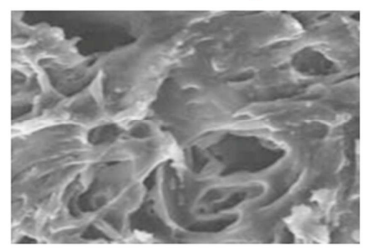

d: $15 \%$ LDPE composites.
Figure 5. Effect of the mixed fillers on the surface morphology of the composites.

From the results of the SEM micrographs shown above, it 
was observed that there were uneven dispersion and agglomeration of filler particles in the polymer matrix; however, there seem to be an improvement on the dispersion of the filler in the composite matrix as the filler load fraction increases. This also confirms the poor mechanical properties of the composites obtained at lower filler load fraction, which indicates, that as the filler load fraction increases there were improvement in some mechanical properties of the composites.

\section{Conclusion}

The fabrication of coconut husk mixed with mango seed shell reinforced low density polyethylene (LDPE) composite, has been successful. The fillers showed their effects on the polymer prepared composites at different filler percentage loadings. Thus, the mechanical properties of the composites produced where found to be dependent on polymer matrixfiller interaction, particle size and dispersion of the filler particles within the matrix. An even dispersion of filler particles within the polymer matrix with the right particle size leads to an improved mechanical properties of low density polyethylene. While an uneven dispersion of the fillers in the polymer matrix due to low mixing, can the attributed to the decrease in mechanical properties of these composite. It is also observed that waste materials such as coconut husk and mango seed shell can be put into industrial use in the production of polymer composites. It is also observed that the fillers resulted in an increase in the mechanical properties of the polymer composites such as flexural strength and hardness this could be attributed to even dispersion of filler in the polymer matrix as could be observed when viewing the results of the surface morphology using scanning electron microscopy procedure.

\section{References}

[1] Ewulonu, C. M and Igwe, I. O, (2012). Properties of Oil Palm empty Fruit Bunch Fibre Filled High Density Polyethylene" International Journal of Engineering andTechnology Vol. 3 (6), 2011-2012, 458-471.

[2] Brydson J. A., (1967). Development of Natural Rubber Technology, Maclaren and Sons Limited, London.

[3] Niranjan, K. (2009). Fundamentals of polymer: Raw Materials, Finish Product, Asoke K. G., New Delhi, pp 54-60.

[4] Lake, R. S (2002). Analysis of High Volume Fraction Irregular Particulate Damping Composites. ASME transachons vol. 12 (4), 175-177.
[5] Jiquao, K. S, Ali J. V and Sianemat N. (2010). "Effect of Particle Size and Volume Fraction on Tensile Properties and of flyash/polyurea Composites". Jiangyali proc. of SPIE. 7 (6): 823-830.

[6] Nowosielski, R., Babilas R., and Dercz, P. (2006). Microstructure of Composite Material with Powders of Barium Ferrite. Journal of Achievement in Materialsand Manufacturing Vol. 7 (1), 117-120. Particle Re.

[7] Abdullah A. H, Rusell, D. S. and Abdul Wahab, A. S. (2011). Reinforced PolymerJournal of Basrah Researchers silence, 7 (3) $36-42$

[8] Anyanwu P. I., and Ogboke, O., (2007). The use of organic fillers as property Enhancement for polymer. International Research Journal of Engineer scienceand Technology. 4 (2) 177-183.

[9] Onuegbu, G. C, Madufor I. C. and Ogbobe O. (2012). The effect of organic filler contents and particle sizes of polymer. Academic Research International: 3 (1): 406-412.

[10] Nwanonenyi, S, C., Obidiegwu, M, U., Onuegbu G, C., (2013). Effects of Particle Sizes, Filler Contents and Compactibilization on the Properties of Linear Low Density Polyethylene Filled Periwinkle Shell Powder. International Journalof Engineering and Science: 2 (2): 1-8.

[11] Obasi H, C., (2015).’Peanut Husk Filler Polyethylene Composite; Effects of Filler Content and Compactiblizer on Properties", Journal of Polymers, Vol 2 (1), Article ID 189289 , p. 9 .

[12] Atuanya C, U., Olaitan, S. A., Azeez, T, O., Akagu C, C., Onukwuli, O. D., and Mentikit M, C., Effects of Rice Husk Filler on Mechanical Properties of Polyethylene Matrix Composites. IJCRR 5 (15), 2013.

[13] Agunsoye, J. O., Talab, S. I., and Sanni, O, S., (2012). A Study of Mechanical Behavior of Coconut Shell Reinforced Polymer Matrix Composites. Journal ofMinerals and Materials Characterization and Engineering 11: 774-779.

[14] Chris-Okafor, P, U., Arinze R, M, U., Nwokoye J, N., Ernest U, U., (2017) Effect of Coconut Husk and Corn Cob as Fillers in Flexible Polyurethane Foam. American Journal of Polymer Science and Technology. 3 (4): 64-69.

[15] Onuegbu T. U., Obianuko N., Mbachu G, U., and Illoameke I, M., (2010); The Effect of Animal Waste (goat femur) as Filler in Flexible Polyether Foam. Journal of basic physical research 1 (1): 5-8.

[16] Ruiju. G, Mohini M, S., and Samir, K. K., (2013), A Feasibility Study of Polyurethane Composite Foam With Added Hardwood Pulp, Industrial Crops and Products. Checkmate Press, New York: 42 (2). 273-279.

[17] Ofora, Pauline, U., Eboatu, Austine, N., Arinze, Rosemarry, U., (2014); Effects ofFillers of Animal Origin on the PysicoMechanical Properties ofUtility Polymer. Journal of Applied Chemistry. 7 (7): 19-23. 